\title{
Fuel Consumption Model for Road Distribution of Petroleum Products in Kenya
}

\author{
Samuel Maina Ngure, Francis Xavier Ochieng, Joseph Thingithu Mailutha \\ The institute of Energy and Environmental Technology (IEET) - JKUAT, P. O. Box 62000-00200, Nairobi, \\ Kenya \\ The institute of Energy and Environmental Technology (IEET) - JKUAT, P. O. Box 62000-00200, Nairobi, \\ Kenya \\ Department of Biomechanical and Environmental Engineering-JKUAT, P. O. Box 62000-00200, Nairobi, \\ Kenya
}

\begin{abstract}
Analyzing and predicting fuel consumption is crucial for the industry stakeholders. However uncertainties play a key role in projecting fuel consumption for a trip. This study therefore had the following objectives: (1) to determine the factors influencing fuel energy demand for road cargo, (2) develop a model to predict the energy (fuel) consumption for road cargo. To achieve these objectives the study used a number of methodologies including: a structured random questionnaires, observations, face to face interviews and focal group discussions to acquire primary data, which was then analyzed using SPSS and Microsoft Excel. Interviews were conducted to collect qualitative data from four truck owners and ten transport managers while questionnaires were used for 90 truck drivers.

The result indicated that personnel characteristics, truck design, road condition and truck operating factors determine an average speed of a vehicle. It was also found that an average speed had a relationship with energy (fuel) consumption of vehicles. Based on this a fuel consumption model was developed which revealed a $90 \%$ or more congruence with actual measured data. The study establishes that if the trucks can be driven at an average speed of 70 to 75 kilometres per hour in Kenya maximum energy savings can be achieved. In conclusion energy conservation and efficiency awareness should be created to various stakeholders not only for maximizing the profits but also in the reduction of energy waste, emission and to attain sustainability in transport sector.
\end{abstract}

Keywords: fuel consumption model, average speed, average trip, fuel consumed per trip, diesel, axles

\section{Introduction}

The transportation of petroleum products in Kenya was mainly carried out using pipeline $72.74 \%$ and roads $27.26 \%$ in year 2005 to 2009 (MOE 2010) on average while railway remained unutilized. The use of road for transportation of petroleum products between Mombasa port and Nairobi continued to increase due to economic growth, population growth and pipeline services where by the pipe between Mombasa and Nairobi carried an average of 4 billion litres instead of 6.4 billion litres of petroleum per year 2009 (Ministry of road, 2009). The petroleum products transportation demand has continued to grow drastically due to opening up of borders between Kenya and her neighbours, and the creation of East African common market with enlarged membership (Kenya, Tanzania, Uganda, Rwanda and Burundi). The implication of this road cargo transportation was high demand for energy, accompanied by high costs of transport, road maintenance, increased air pollution, road accidents and loss of property.

Not much was done to estimate the energy demand and expected demand trends in the coming years of enhanced economic growth leading to the Kenya Vision 2030. This was largely due to lack of necessary data, appropriate models, qualified personnel and required institutions. Despite limitations in theory and data availability, a wide range of models have been developed to explore trends at global scales and in developed countries. These models are partly developed from different scientific paradigms, which may lead to different interpretations of the past and different expectations of the future (Löschel, A., 2002). However little effort has been put in specializing on transport energy model and statistical data related to transport is more deficient. The perception that a complex model with extensive input data produces more accurate results might not always be true. Simple models can sometimes yield results as accurate as more complicated techniques (Armstrong, 2001). As Koomey, 2002, pointed out, energy demand modelers should ask whether the modeling tool is drives or supports the process of developing a coherent scenario and credence to deal with uncertainties. This study thus proposes a model to estimate the energy (fuel) consumption for distribution of petroleum products in Kenya. 


\section{Materials And Method}

The study utilized both primary and secondary data. Secondary data were obtained from official statistical publications including Statistical Abstracts, Economic Survey 2010, publication from PIEA (Petroleum Institute of Eastern Africa).The study used structured random questionnaires, observations, face to face interviews and focal group discussions to acquire primary data which was then analyzed using SPSS11.5 and Microsoft Excel. Questionnaire was used to collect data on first, personal characteristics which include respondent's age, gender and education level. Secondly truck designs, which include the type of fuel truck used, engine size, number of wheels, number of axles, type of the vehicle, tire weight, loading capacity and gross weight and lastly truck operating factors which were average speed, number of trips, trip distance, number of times the vehicle undergoes service annually, the distance travelled before a vehicle undergoes service, distance travelled using 1 litre of fuel when loaded and unloaded, and the amount of fuel consumed in a trip. Face to face interview and focal group discussion was used to establish the accuracy of the data regarding average speed, fuel consumption per trip and total gross weight which was done with transport managers and truck owners. Observations were used to establish the average speed with drivers. Finally measuring, observation and review of manufacturers specifications was used to establish the frontal area and aerodynamic drag. A sample size of 104 was used which includes 4 truck owners, 10 transport managers and 90 truck drivers. Research concentrated mainly on the road between Nairobi $\left(1^{0}\right.$ South, $36^{\circ}$ East) and Mombasa ( $4^{0}$ South, $39^{\circ}$ East) which covers a distance of 485 kilometres. The road was suitable for this study because it connect Mombasa port to the biggest urban area of the region, Nairobi. The area was also served by railway and pipeline network. The study also involved visiting the offices of transportation companies located in Nairobi and Mombasa.

\subsection{FUEL CONSUMPTION ESTIMATION}

There are several factors that influence fuel consumption. First the fuel consumption is influenced by the energy content of the fuel. Secondly from Newton's second law, it can be demonstrated that the net force on a vehicle in the direction of motion is proportional to its acceleration and is required to overcome the aerodynamic, rolling resistance and grade résistance. Therefore the fuel consumption is also influenced by engine size, number of wheels, number of axles, distance, weight, carriage, average speed, road grade and surface roughness. Thirdly driver personal characteristics which are age, education and gender. And finally the Thoresen (2003) lookup tables were used to calculate the coefficients of the basic fuel consumption equation which are $\mathrm{A}, \mathrm{B}$ and $\mathrm{C}$.

Fuel Consumption $=\left(\mathrm{A}+\frac{\mathrm{B}}{\mathrm{V}}+\mathrm{CV}^{2}\right) *\left[\begin{array}{c}1+\text { Correction factors } \\ \text { of } \\ \text { road roughness }\end{array}\right] \ldots .2$

Thoresen (2003)

Where $\mathrm{V}$ is the average speed measured over a distance, including stops

A is parameter associated with fuel consumed to overcome rolling resistance, approximately proportional to vehicle weight.

$\mathrm{B}$ is parameter approximately proportional to fuel consumption while idling.

\subsection{FACTORS INFLUENCING FUEL ENERGY DEMAND}

\section{Results And Discussions}

The study established that this sector was dominated by males. It found that $98.1 \%$ were males and only $1.9 \%$ was females. The survey carried out by Transport research laboratory (1999) indicated that women drivers drive about $1 \mathrm{mph}$ slower than men. It was also established that $89.4 \%$ of drivers, mangers and truck owners respectively were form1-4 graduates. This therefore requires introduction of energy conservation and efficiency together with implication of fuel consumption to environmental pollution and emission at secondary school level. It was further found that majority of the drivers and transport mangers in the sector were at age group of 37-48 years. This age group according to TRL (1999) tends to drive at an average speed of $44.3 \mathrm{mph}$. The study found that trucks used for distribution of petroleum products in Kenya had the following characteristics an average of total gross weight of 48 tonnes, average of 22 wheels, average of 420 horse power and driven at an average speed of $40-60 \mathrm{~km} / \mathrm{hr}$ per trip.

Figure 1 shows the relationship between engine size (hp) and total gross weight (tonnes).It indicates that as the engine size increases the total gross weight also increases. It was also observed that as the gross weight of truck increases the number of axles and wheels also increases. It shows a direct linear relationship between the two factors. Therefore the engine size determines the number of axles and wheels. 


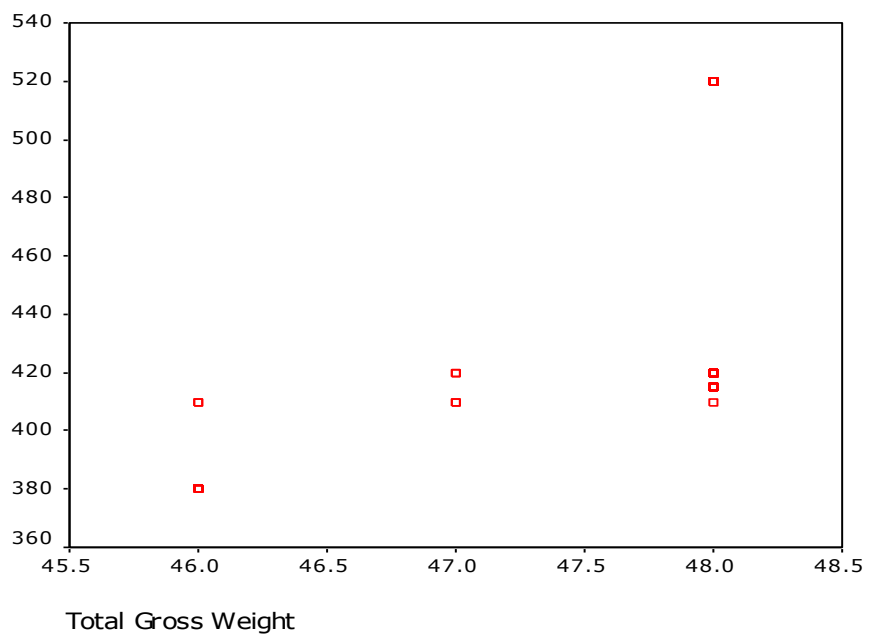

Figure 1 Engine Size versus Total Gross Weight

Table 1 shows the Pearson correlations between average speed per trip (km/hr) and engine size (hp). The table indicates that there was a positive correlations between the two variables $(\mathrm{r}=.458, \mathrm{p}=.000)$ with engine size being associated with average speed per trip. Having established the relationship between engine size and total gross weight from figure1.And having established positive correlations between engine size (hp) and an average speed per trip $(\mathrm{km} / \mathrm{hr})$.It can be concluded that engine size and total gross weight also determines the average speed of a truck. Fuel consumption is highly dependent on many different traffic characteristics with speed and acceleration being significant factors affecting fuel consumption rates. Generally, fuel consumption rates increase as speed and acceleration increases. Also, fuel consumption rates are reduced by engine friction, tires and accessories such as power steering and air conditioning at low speeds and are dominated by the effect of aerodynamic drag on fuel efficiency at high speeds (Ross 1993a).Vehicle characteristics such as number of wheels, gross weight and loading capacity have relationship with the friction forces of a truck.

Table 1Correlations between Average Speed per Trip and Engine Siz€

\begin{tabular}{|c|c|c|c|}
\hline & & $\begin{array}{c}\text { Average } \\
\text { Speed/Trip }\end{array}$ & $\begin{array}{l}\text { Engine } \\
\text { Size }\end{array}$ \\
\hline \multirow{3}{*}{$\begin{array}{c}\text { Average } \\
\text { Sp eed/Trip }\end{array}$} & $\begin{array}{l}\text { Pearson } \\
\text { Correlation }\end{array}$ & 1 & $.458 * *$ \\
\hline & Sig. (2-tailed) & . & .000 \\
\hline & $\mathrm{N}$ & 104 & 102 \\
\hline \multirow{3}{*}{ Engine Size } & $\begin{array}{l}\text { Pearson } \\
\text { Correlation }\end{array}$ & $.458 * *$ & 1 \\
\hline & Sig. (2-tailed) & .000 & . \\
\hline & $\mathrm{N}$ & 102 & 102 \\
\hline
\end{tabular}

**. Correlation is significant at the 0.01 level (2-tailed).

The other important factor to consider was source of energy. The study established that all of vehicles used diesel as sources of energy. According to the Abare (1993) and Affeck (2002) the gross energy content of the automotive diesel is $38.5 \mathrm{MJ}$ per litre. The energy contents of fuel determined the amount of work done. The highway related factors such as steep upgrades and poor road surface conditions also reduce fuel efficiency. On steep upgrades, vehicles require a heavy power output from their engines, consuming more fuel than under normal conditions. Also, rough roads can lead to significant incremental increases in fuel consumption by influencing the rolling resistance and aerodynamic drag generated. At typical highway speeds, a vehicle tested on a rough road increased its fuel consumption by five percent over a vehicle tested on a normal quality road, (Baker 1994). Figure 2 shows the average speed trucks used for distribution of petroleum in Kenya were driven. These trucks are restricted to carry a maximum of total gross weight of 48 tonnes according Kenya Traffic acts chapter 403, (1993) Revised Edition (2009). It indicates that $92.3 \%$ were driven at an average speed of between $41-60 \mathrm{~km} / \mathrm{hr}$ and $7.7 \%$ driven at an average speed of between $61-80 \mathrm{~km} / \mathrm{hr}$. The road between Mombasa and Nairobi had steep road gradient and traffic congestion this may had contributed to the speed. Also at an average speed of less than $60 \mathrm{~km} / \mathrm{hr}$ rolling resistance becomes the major forces to overcome in this particular road. 


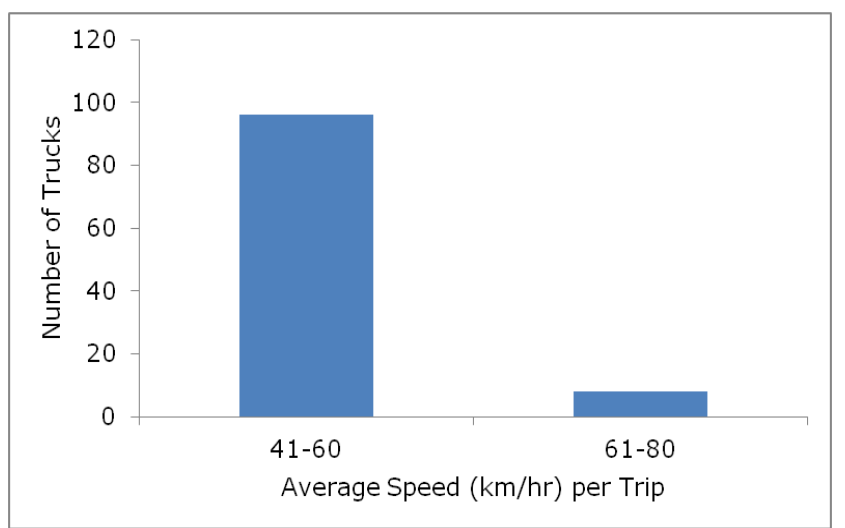

Figure 2 Numbers of Trucks versus Average Speed $(\mathrm{km} / \mathrm{hr})$ per Trip

\subsection{FUEL CONSUMPTION MODEL, RESULTS, VALIDATION AND SIMULATIONS}

From the results and discussions it's clear that all other factors affect the average speed of the vehicle. And therefore this study adopts equation 2 with speed as the only factor to be considered. This equation was established to work well on this road but may not yield the same results with other roads. Therefore study must be conducted before implementing it into the other roads. Equation 2 is the fuel consumption model and the effects of various values of speed are shown in figure 4 ;

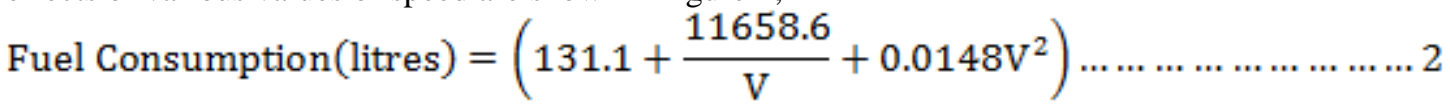

Where $\mathrm{V}$ is the average speed $(\mathrm{km} / \mathrm{hr})$ per trip

Figure 3 shows fuel use as a function of average speed $(\mathrm{km} / \mathrm{hr})$ per trip.It indicates that fuel use decreases rapidly for low speeds, reaches a minimum at a speed of $50 \mathrm{~km} / \mathrm{hr}$ and increases gradually thereafter this is due to the rolling resistance force.On the second part increase in speed above optimum result increase of fuel use which is required to overcome aerodynamic drag. The data from questionnaires indicated that trucks driven at an average speed of 41-60 kilometres per hour consumed 400 litres of diesel while those driven at average speed of 61-80 kilometres per hour consumed 360 litres of diesel.The model shows that truck travelling at an average speed of $50 \mathrm{~km} / \mathrm{hr}$ will consume 401 litres while whose travelling at an average speed of $70 \mathrm{~km} / \mathrm{hr}$ will consume 370 litres These trucks are restricted to carry a maximum of total gross weight of 48 tonnes according Kenya Traffic acts chapter 403, (1993) Revised Edition (2009). Therefore results obtained using the model developed in equation 2 indicates less disparity between observed and modeled. Therefore the performance of calibrated model was practically satisfactory.

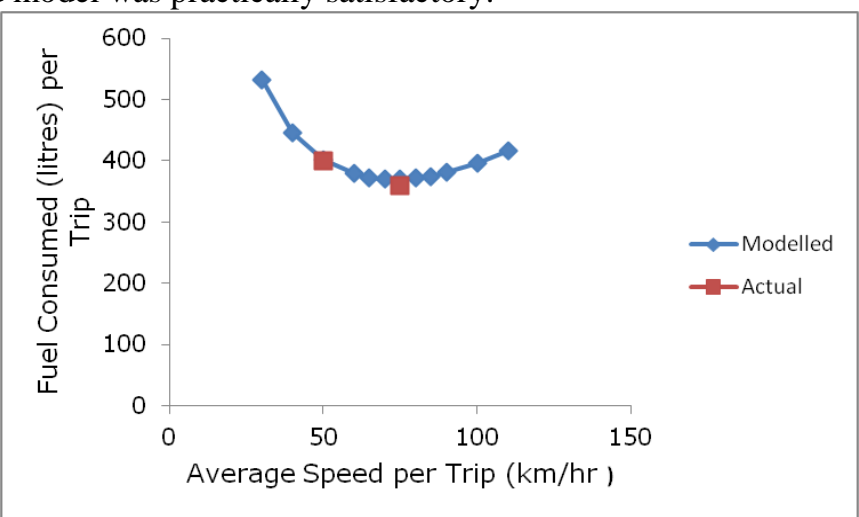

Figure 3 Fuel Consumed (litres) per Trip versus Average Speed (km/hr) per Trip

\section{Conclusions And Recomendations}

The model establishes that an average speed had a polynomial relationship with fuel (energy) consumption.The model shows possibilities for improving fuel efficiency suggected by the fuel consumption curve were quite large, at speed of between $70 \mathrm{~km} / \mathrm{hr}$ and $75 \mathrm{~km} / \mathrm{hr}$ compared to a speed of below $50 \mathrm{~km} / \mathrm{hr}$ and a speed of over $100 \mathrm{~km} / \mathrm{hr}$ with a saving of approximateraly 30 litres diesel per trip.However this speed cannot be maintained during a trip because of road conditions and other traffic issues which include police stops and weighbridge. The model further indicates the two forces affecting the energy consumption of a moving vehicle, at high speed of over $80 \mathrm{~km} / \mathrm{hr}$ aerodynamic forces takes effect while at lower speed of less than $60 \mathrm{~km} / \mathrm{hr}$ rolling 
resistance forces dominant.This study establishes that trucks were driven at lower speed of between $40-60 \mathrm{~km} / \mathrm{hr}$ therefore rolling resistance forces is the major dominant.It therefore requires the designer of trucks and roads to concentrate on technologies to reduce rolling resistance forces of the vehicles. The study found that majority of respondant were form 1-4 secondary school graduate.Thus requires that energy conservation and efficiency together with implication of fuel consumption to environmental pollution and emission should be introduced at secondary school level.

\section{Acknowledgements}

We wish to thank the IEET, JKUAT for granting an opportunity to study.

\section{References}

[1]. ABARE (1993).”Energy: Demand and supply projection, Australia 1992-93 to 2004-05.”Research Report 93-2, Australian Bureau of Agricultural and Resource Economics, Canberra

[2]. Affleck (2002).”Comparison of Greenhouse Gas Emission by Australian Intermodal Rail and Road Transport.”Affleck Consulting, Brisbane.

[3]. Ahn, K.Rakha, H.Trani, A.A. and Van Aerde, M. (2002).'Estimating vehicle fuel consumption and emissions based in instantaneous speed and acceleration levels."Journal of transportation engineering

[4]. An, F., and M. Ross (1993a), Model of Fuel Economy with applications to Driving Cycles \& Traffic Management, Transportation Research Record, Washington, D.C.

[5]. Baker, M. (1994) Fuel Consumption and Emission Models for Evaluating Traffic Control and Route Guidance Strategies, Mater thesis, Queen's University, Kingston, Ontario, Canada

[6]. Biggs, D.C.(1988),"ARFCOM-models for estimating light to heavy vehicle fuel consumption" ARR NO.152 Australian Road Research Board, Victoria.

[7]. CSIRO, PPK and USA (2002).’Modeling Responses of Urban Freight Patterns to Greenhouse Gas Abatement measures: Draft Interim Report" .CSIRO Division of Building Construction and Engineering; PPK Environment and Infrastructure; and Transport System Centre, University of South Australia, North Ryde 1670,New South Wales

[8]. Davis, S.C. (1994) Transportation Energy Data Book: Edition 14. ORNL-6798. Center for Transportation Analysis, Energy Division, Oak Ridge National Laboratory, Tenn.

[9]. Essenligh, R.H., Shull, H.E., Blackadar, T., and Mckinstry, H. (1979)."Effect of vehicle size and engine displacement on automobile fuel consumption." Transportation Research A, 13 (A), 175-177.

[10]. Ferreira, L. (1985). "Modeling urban fuel consumption, some empirical evidence.” Transportation Research A, 19 A (3), $253-268$.

[11]. Traffic acts of Kenya, chapter 403, (1993) Revised Edition (2009), Nairobi.

[12]. Gogel, J.I. and Watson, H.C. "Relationship between road track cost and heavy vehicle fuel consumption." Fourth International Symposium on heavy vehicle weights and dimensions, Ann Arbor, Michigan, USA, 31-38.

[13]. Greenwood, I.D., and Bennett, C.R. (2001).”Modeling road user and environmental effects in HDM-4.” ISBN 2-84060-103-6, Birmingham.

[14]. Löschel, A. (2002). Technological change in economic models of environmental policy: A survey. Ecological Economics, 43(23), 105-126.

[15]. Medlock, K. B., III, \& Soligo, R. (2001),'Economic development and end-use energy demand”, Energy Journal, vol.22, no.2, pp. 77.

[16]. Quimby A R, Maycock G, Palmer C and Grayson G B (1999). Drivers' speed choice: an in-depth study. TRL Report TRL326. Transport Research Laboratory, Crowthorne. 